\title{
Fishing penetration injuries
}

\author{
I Dudkiewicz, M Salai, A Blankstein, A Chechik
}

\begin{abstract}
Background-Fishing involves millions of people throughout the world and is considered a pleasant and harmless sport. However, many kinds of injury can occur. Penetrating injuries to the extremities by fishing equipment such as hooks and harpoons, and even by scales, or infection from penetration of scales etc are relatively common although hardly ever reported in the literature.

Methods-Illustrative cases of penetrating fishing injuries are presented and discussed, with suggestions for the recommended management of these types of injury.

Results-Most of these objects are designed to catch and hold resisting fish, so are usually sharp and narrow in the front and wider in the rear with or without spurs. Because of their very irregular shape, simple extraction by pulling is not recommended, because further damage may occur.

Conclusions-The use of the appropriate imaging modalities, a full knowledge of the contours of the object, and careful preplanning of the method of treatment are very important.

(Br F Sports Med 2000;34:459-462)
\end{abstract}

Keywords: fishing; penetration injuries; extraction; imaging modalities

There are two main aspects of fishing related injuries. One is the "mechanical" aspect, caused by penetrating foreign bodies; this is discussed in this paper. The other is infection. Although fishing injury related infections are quite common and usually trivial, they can cause severe damage $^{12}$ and even death. ${ }^{3}$ This paper deals mainly with the "mechanical" nature of the injuries; discussions on infections deriving from them can be found in the appropriate literature.

Injuries caused by penetration of foreign bodies such as hooks, harpoons, special fishing knives, and even scales are relatively common in fishing, both professional and amateur. ${ }^{4-8}$ Most of these objects are designed to catch and hold resisting fish and are therefore usually sharp and narrow in the front and wider in the rear with or without spurs. Because of their very irregular shape, simple extraction by pulling is not recommended, because further damage may occur. We present illustrative cases of such injuries from a group of patients treated during 1995-1997, and also suggest an appropriate clinical approach.

\section{Materials and methods}

During 1995-1997, 300 patients with penetrating injuries were treated in our emergency department. The causes of the injuries were as follows: 169 were due to work accidents, 53 to road accidents, 45 to domestic accidents, and 33 to fishing. Of the patients with fishing related injuries, 24 were men. Their ages ranged from 7 to $81: 13$ were in the 6-20 year age group, 15 in the $20-40$ year age group, and five were older than 40 . The injuries were mostly located in the extremities but also in the trunk. They were mainly inflicted by hooks of various size, but two were caused by harpoons and one by small scales.

All patients were treated under local anaesthesia in the emergency room, except one who needed treatment under general anaesthesia in the operating theatre.

All patients received antibiotic after removal of the object, usually amoxicillin/clavulunate 500/125 mg (Augmentin) three times a day, and also toxoid tetanus booster.

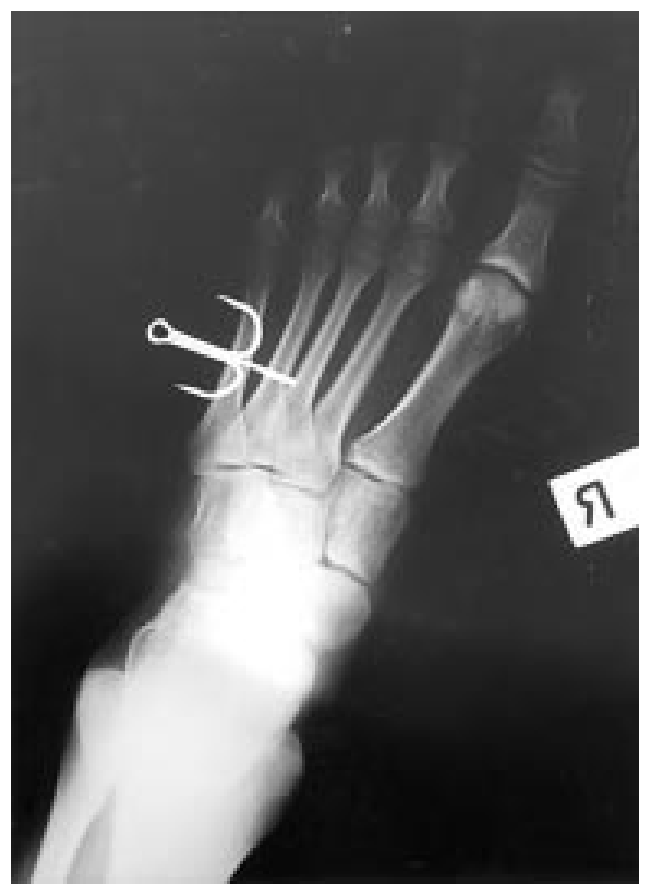

Figure 1 Large fishing rod hook penetrating the foot. 


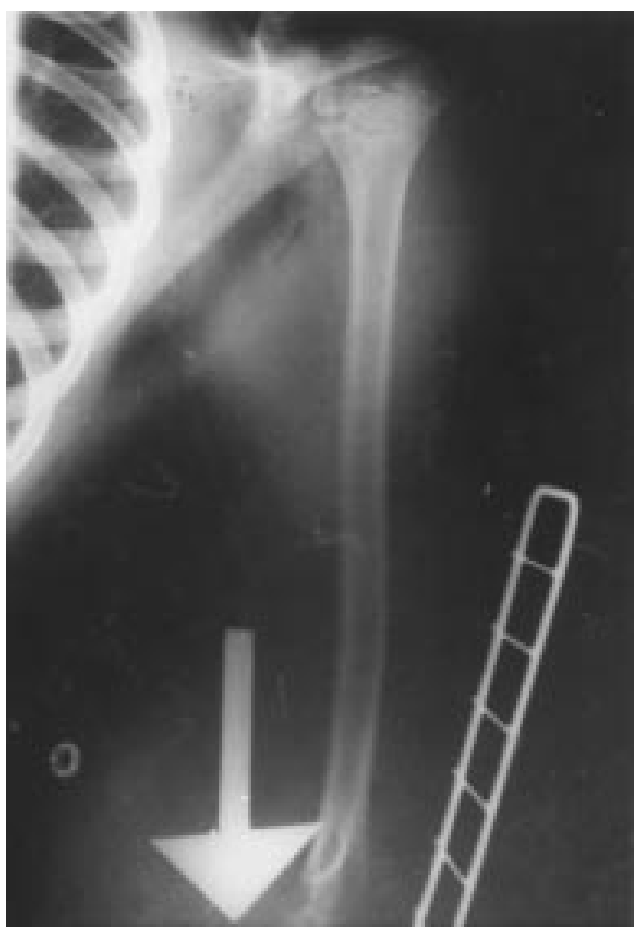

Figure 2 Large fishing spear lodged in the soft tissue of the distal arm.

\section{Illustrative cases}

(1) A young man with a large fishing rod hook penetrating his foot. On examining another hook from the outside, it was clear from the spurs that had not penetrated that it could not simply be extracted by pulling. An $x$ ray photograph of the foot (fig 1) confirmed the irregularity of the object. The hook was removed by using it as a hinge, making a local cut above its end, and pushing it forward while rotating it so as to avoid any additional tearing of soft tissue.

(2) A 17 year old girl who had been hit in the arm with a large fishing spear shot from a fishing gun which was stuck in the soft tissue of the distal arm with no apparent neurovascular damage (fig 2). Owing to its location, large size, and potential to damage vulnerable adjacent neurovascular structures, the spear was extracted in the operating theatre after surgical exposure by pushing it forward in the direction of the initial entry under direct vision. Thus less damage was inflicted on the surrounding tissue. The patient made an uneventful recovery and resumed physical activity.

\section{Discussion}

Fishing is a sport enjoyed by millions of people throughout the world. It involves all age groups, and does not require special training or fancy equipment. However, as in most sports, injuries caused by falls, shoulder injuries, and especially penetrating injuries can occur. During routine emergency work, injuries caused by penetration of foreign objects are commonly encountered.

Many reports in the orthopaedic literature, as well as in other fields of medicine and traumatology, have discussed the treatment of foreign bodies, but very few refer particularly to penetrating fishing injuries in the extremities. ${ }^{4}$ More is written about eye injuries, perhaps because of the potentially devastating consequences of such an injury, although even an orthopaedic injury that is considered trivial and simple can cause severe incapacitating damage if treated incorrectly. ${ }^{5-8}$ In most instances when the foreign object involved is sharp, with smooth edges and uniform or unchanging contours (such as needles and small headed nails), its extraction is relatively simple. In particular, when one end of the object protrudes outside the extremity, the entire object may be pulled out manually or by using an instrument with a firm grip.

When the shape of the object involved is not uniform, such as most fishing rod hooks, harpoons, and spears, further information on its exact shape and location is of utmost importance when planning how to extract it. As most of these objects are metal, simple radiographs are adequate for this purpose. Other imaging modalities such as ultrasound or computed tomography should be used for

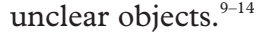

Most penetrating objects can be extracted under local anaesthesia in the emergency department. When neural or vascular damage is a possibility or actually present on admission, safe extraction requires general or regional anaesthesia, widening of the penetrating wound, and careful exploration of the object tract to prevent further damage to neurovascular structures.

The above are just a few examples illustrating the importance of using appropriate imaging modalities to obtain a full knowledge of the contours of the object and careful advanced planning of the method of extraction.

These guidelines are put forward to alert doctors to the potential problems of common fishing injuries caused by irregularly shaped penetrating objects and to prevent the possible additional damage that can be caused when they are simply pulled out by inexperienced practitioners.

This paper deals only with penetration injuries. As fishing is such a popular sport, more studies are required to evaluate the exact extent of all other types of fishing injury.

1 de Wind CM. Severe infections following fish bone and spine injuries. Trop Doct 1996;26:168-9.

2 Murphey DK, Septimus EJ, Waagner DC. Catfish-related njury and infection: report of two cases and review of the literature. Clin Infect Dis 1992;14:689-93.

3 Yoshida N, Iwamoto M, Mukae $\mathrm{H}$, et al. A case of fatal sepsis due to Vibrio vulnificus. Kansenshogaku Zasshi 1990;64: Sis due to $236-42$.

4 McCallum WG, Fromm RE Jr. Fish scale: an unusual foreign body. Am f Emerg Med 1995;13:419-20.

5 Aiello LP, Iwamoto M, Guyer DR. Penetrating ocular fish-hook injuries. Surgical management and long-term visual outcome. Ophthalmology 1992;99:862-6.

6 Ciulla TA, Mukai S, Miller JW. Severe penetrating eye traumas caused by fish pick accidents. Retina 1996;16:219-21.

7 Y'uksel N, Elibol O, Ca'glar Y. Penetrating corneal fish-hook injury. Ophthalmologica 1994;208:112-13.

8 Gutierrez A, Gil L, Sahuquillo J, et al. Unusual penetrating craniocerebral injury. Surg Neurol 1983;19:541-3.

9 Reiner B, Siegel E, McLaurin T, et al. Evaluation of soft tissue foreign bodies: comparing conventional plain film radiography, computed radiography printed on film, and radiography, computed radiography printed on film, and
computed radiography displayed on a computer workstation. AfR Am f Roentgenol 1996;167:141-4.

10 Bray PW, Mahoney JL, Campbell JP. Sensitivity and specificity of ultrasound in the diagnosis of foreign bodies in the hand. $\mathcal{F}$ Hand Surg [Am] 1995;20:661-6. 
11 Lammers RL, Magill T. Detection and management of foreign bodies in soft tissue. Emerg Med Clin North Am 1992; eign bodies

12 Donaldson JS. Radiographic imaging of foreign bodies in the hand. Hand Clin 1991;7:125-34.
13 Banerjee B, Das RK. Sonographic detection of foreign bodies in the extremities. Br F Radiol 1991;64:107-12.

14 Shiels WE 2nd, Babcock DS, Wilson JL, et al. Localization and guided removal of soft tissue foreign bodies with sonography. AfR Am F Roentgenol 1990;155:1277-81.

\title{
Take home message
}

Fishing is a very common sport throughout the world and it can involve many kinds of injury, especially penetrating injuries. Doctors should be alert to the potential problems of extracting irregularly shaped objects such as hooks, harpoons, and scales. The use of appropriate imaging modalities, a full knowledge of the contours of the object, and careful preplanning of the method of treatment are very important.

\section{Broken arm wrestler}

\author{
A Khashaba
}

\section{Abstract}

An unusual injury following an arm wrestle is presented, that of a fractured humerus.

(Br F Sports Med 2000;34:461-462)

Keywords: humerus; arm wrestle

\section{Case report}

This patient was an otherwise fit 24 year old chartered surveyor, who was admitted to casualty with a swollen painful right arm. He was a well built muscular man who had drunk 3 pints of beer before embarking on a one off arm wrestle challenge with an equally built yet taller man (and hence with longer forearms), who regularly arm wrestled. His only medication was ventolin and becotide inhalers for mild asthma.

The patient was in an offensive (winning) position for the first 30 seconds approximately, then the wrestle was restarted because each wrestler wanted to regain a comfortable sitting position. The patient was then in the neutral to defensive position for about ten seconds when he felt his arm give way and crack with excruciating pain while defending at an obtuse angle of about $100^{\circ}$ (where neutral is regarded as $90^{\circ}$ ).

Examination disclosed a tender dominant right arm just above the elbow, with distal neurovascularity intact. Radiographs of the elbow showed a short spiral fracture of the distal third of the humerus (fig 1).

\section{Discussion}

Fracture of the humerus following an arm wrestle in a young fit man is a rare occurrence, ${ }^{1}$ as is fracture-separation of the medial humeral epicondyle in adolescents. ${ }^{2}$ The shoulder joint is actively internally rotated against the opponent while the elbow is fixed in flexion, resulting in enormous violent torque forces across the humeral shaft. ${ }^{3}$ This patient's diet was adequate with no evidence of nutritional deficiency. Usually the musculotendinous

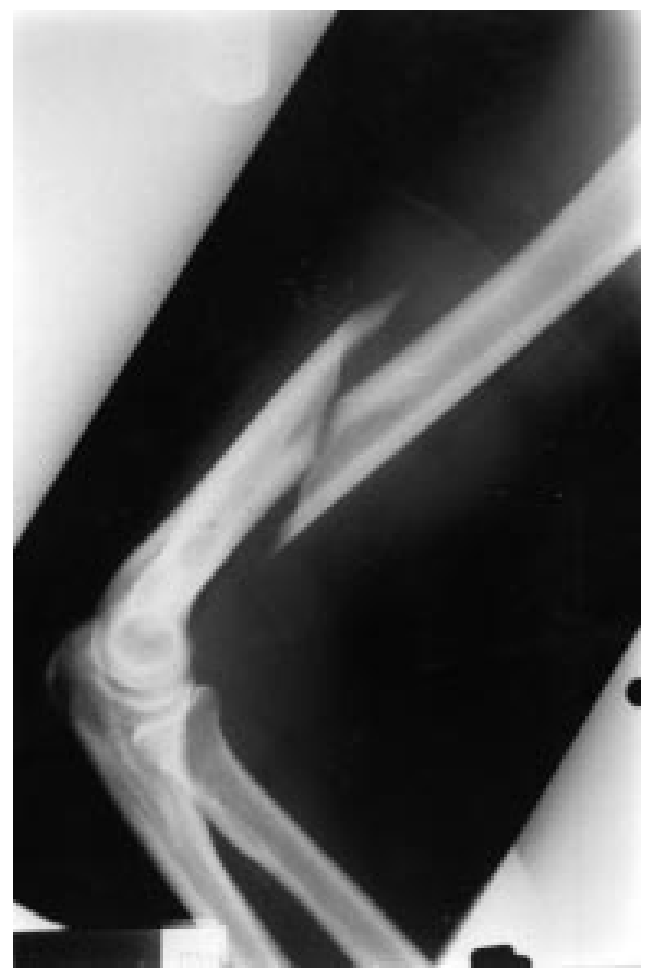

Figure 1 Lateral elbow radiograph showing short spiral fracture of the humerus (right side).

structures are the limiting factor in arm wrestling, but in this particular case they were not, either because the proprioceptive awareness of the patient was reduced because of the alcohol and late night and/or he was overmuscular for his bony size, in the sense that, although he was generally muscular, he did not have the humeral cortical bone hypertrophy to match his muscularity because he was not a regular arm wrestler. ${ }^{4}$ Furthermore, his opponent had a longer forearm and consequently a moment-torque advantage. 
This type of arm wrestling injury tends to occur when one arm wrestler tries to force the match in an effort to win or to change the tide of the contest. This results in the defending arm wrestler taking or being forced to take a posture in which his centre of gravity and therefore his body weight has shifted. As the offensive wrestler continues with the attack, the defender's internal rotator shoulder muscles suddenly and passively stretch and change from their maximally concentric contraction to an eccentric compensatory contraction, resulting in an intense rotational force with subsequent humeral fracture. ${ }^{25}$ This fracture was treated by means of a collar and cuff in a net body bandage.

1 Heilbronner DM, Manoli A 2nd, Morawa LG. Fractures of the humerus in arm wrestlers. Clin Orthop 1980;149:169-71.

2 Ogawa K, Ui M. Fracture-separation of the medial humeral epicondyle caused by arm wrestling. f Trauma 1996;41: $494-7$.

3 deBarros JW, Oliveira DJ. Fractures of the humerus in arm wrestling. Int Orthop 1995;196:390-1.

4 Jones HH, Priest JD, Hayes WC, et al. Humeral hypertrophy in response to exercise. $\mathcal{F}$ Bone foint Surg [Am] 1977;59:

5 Ogawa K, Ui M. Humeral shaft fracture sustained during arm wrestling: report on 30 cases and review of the literaarm wrestling: report on 30 ca
ture. $\mathcal{F}$ Trauma $1997 ; 42: 243-6$.

Take home message

Arm wrestling is an enjoyable ego boosting sport, but it is not benign and should not be attempted on a competitively serious level by those who are not regularly trained arm wrestlers. 